\title{
Fittings losses in paste flow design
}

\author{
P.T. Slatter RMIT University, Australia \\ V.G. Fester Cape Peninsula University of Technology, South Africa
}

\begin{abstract}
Accounting accurately for the losses that arise from pipe fittings, such as valves, becomes a significant and important issue, given the current emphasis on energy reducing technologies. Efficient design is only possible if reliable loss coefficient data are available. For paste slurries which are in use in many industrial settings, this situation is exacerbated by the necessity to use less water, resulting in laminar flow designs becoming more common. Against this is the prevalent design reality that whilst reliable loss coefficient data are available for turbulent Newtonian flow, this is simply not the case for laminar flow. The objective of this paper is to show that fittings losses become much more prominent in laminar flow design. Work done by the authors for the measurement of loss coefficient data on diaphragm valves is reviewed and updated. This work, which is particularly important for paste flow applications, is then used to illustrate the importance of laminar flow loss coefficient data in the context of a practical design example. Pumping power requirement inaccuracies of the order of $50 \%$ are illustrated. The literature available to the paste piping designer contains a direct contradiction, and further research on this important practical issue is called for.
\end{abstract}

\section{Introduction}

The well known Crane design manual (1999) states that "the resistance coefficient of a valve is independent of Reynolds number, and may be considered as a constant under all conditions of flow, including laminar flow". The aim of this paper is to present arguments which show that this is clearly not true, and that an accurate analysis of this important industrial design problem can significantly improve pumping power requirement prediction. Given the current emphasis on energy reducing technologies, accounting accurately for the losses that arise from pipe fittings, such as valves, becomes a significant and important issue. However, efficient design is only possible if reliable loss coefficient data are available. The accurate estimation of the additional energy losses caused by pipe fittings, such as valves, is important for determining the correct pump size (Massey, 1970). The frictional losses arising from pipe fittings are often referred to as 'minor' losses and are normally neglected when they constitute less than $5 \%$ of the total frictional head losses in the straight pipes (Streeter and Wylie, 1985). However, in shorter pipeline lengths, such as those typically found in the process industry, these 'minor' losses can easily sum up to exceed the losses in the straight pipes (Edwards et al., 1985). For fine particle paste slurries which are in use in many industrial settings, this situation is exacerbated by the necessity to use less water, resulting in laminar flow designs becoming more common. Against this is the prevalent design reality that whilst reliable loss coefficient data are available for turbulent flow, this is simply not the case for laminar flow. The objective of this paper is to show that laminar flow fittings losses become much more prominent in laminar flow design. Firstly, work done by the authors for the measurement of loss coefficient data is reviewed and updated. Of special interest is the work on diaphragm valves which is particularly important for paste flow applications, and directly contradicts the extract from the Crane Co. (1999) paper. This work is then used to illustrate the importance of the laminar flow loss coefficient data in the context of a practical design example.

\section{Theory and literature}

\subsection{Rheological modelling}

The Bingham plastic rheological model can be used to characterise the viscoplastic nature of pastes (Govier and Aziz, 1972). The constitutive rheological equation is:

$$
\tau=\tau_{\mathrm{y}}+\mathrm{K} \dot{\gamma}
$$


where:

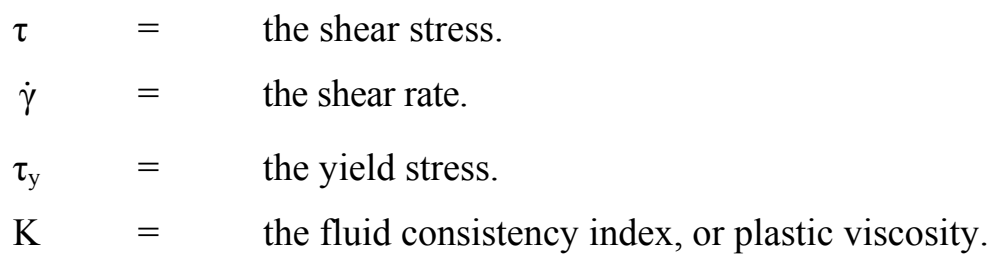

\subsection{Fittings head loss}

On dimensional grounds, the head loss in a fitting, $\mathrm{h}_{\text {fitt }}$, will depend upon the fluid velocity, fluid properties and the geometry of the fitting as follows (Edwards et al., 1985):

$$
\frac{2 \mathrm{gh}_{\text {fitt }}}{\mathrm{V}^{2}}=\mathrm{fn} \text { (Reynolds number, geometry) }
$$

This can be expressed as a function of the velocity energy head and is usually taken as a direct proportionality:

$$
\mathrm{h}_{\text {fitt }}=\mathrm{k}_{\text {fitt }} \frac{\mathrm{V}^{2}}{2 \mathrm{~g}}
$$

Hence, the loss coefficient of the fitting, $\mathrm{k}_{\mathrm{fitt}}$, is given by:

$$
\mathrm{k}_{\text {fitt }}=\mathrm{h}_{\text {fitt }} \frac{2 \mathrm{~g}}{\mathrm{~V}^{2}}
$$

This can also be expressed in terms of pressure drop because $\Delta \mathrm{p}=\rho \mathrm{g} \Delta \mathrm{h}$ and becomes:

$$
\mathrm{k}_{\text {fitt }}=\frac{\Delta \mathrm{p}_{\text {fitt }}}{\frac{1}{2} \rho \mathrm{V}^{2}}
$$

where:

1. $\mathrm{k}_{\mathrm{fitt}}$ is the non-dimensionalised difference in overall pressure between the ends of two long straight pipes when there is no fitting and when the real fitting is installed. This is shown in Figure 1.

2. $\Delta \mathrm{p}_{\text {fitt }}$ is the pressure loss across the fitting. The flow lengths over which pressure losses starts from a few diameters upstream to several pipe diameters downstream of the actual length of the fitting. This is known as the region of influence or interference. $\Delta \mathrm{p}_{\text {fitt }}$ should be measured across this region. It can be either the measured static pressure drop $\left(\Delta \mathrm{p}_{\mathrm{s}}\right)$ or the total pressure that is $\Delta \mathrm{p}_{\text {tot }}=\Delta \mathrm{p}_{\mathrm{s}}+1 / 2 \rho \mathrm{V}^{2}$. Clearly, it is therefore important for all to state whether $\mathrm{k}_{\mathrm{fitt}}$ is based on the static or total pressure.

3. $\rho$ is the density of the fluid.

4. $\mathrm{V}$ is the mean flow velocity in the pipe. If there is a change in pipe diameter, the convention is to use the higher mean flow velocity of either the upstream or the downstream pipe. 


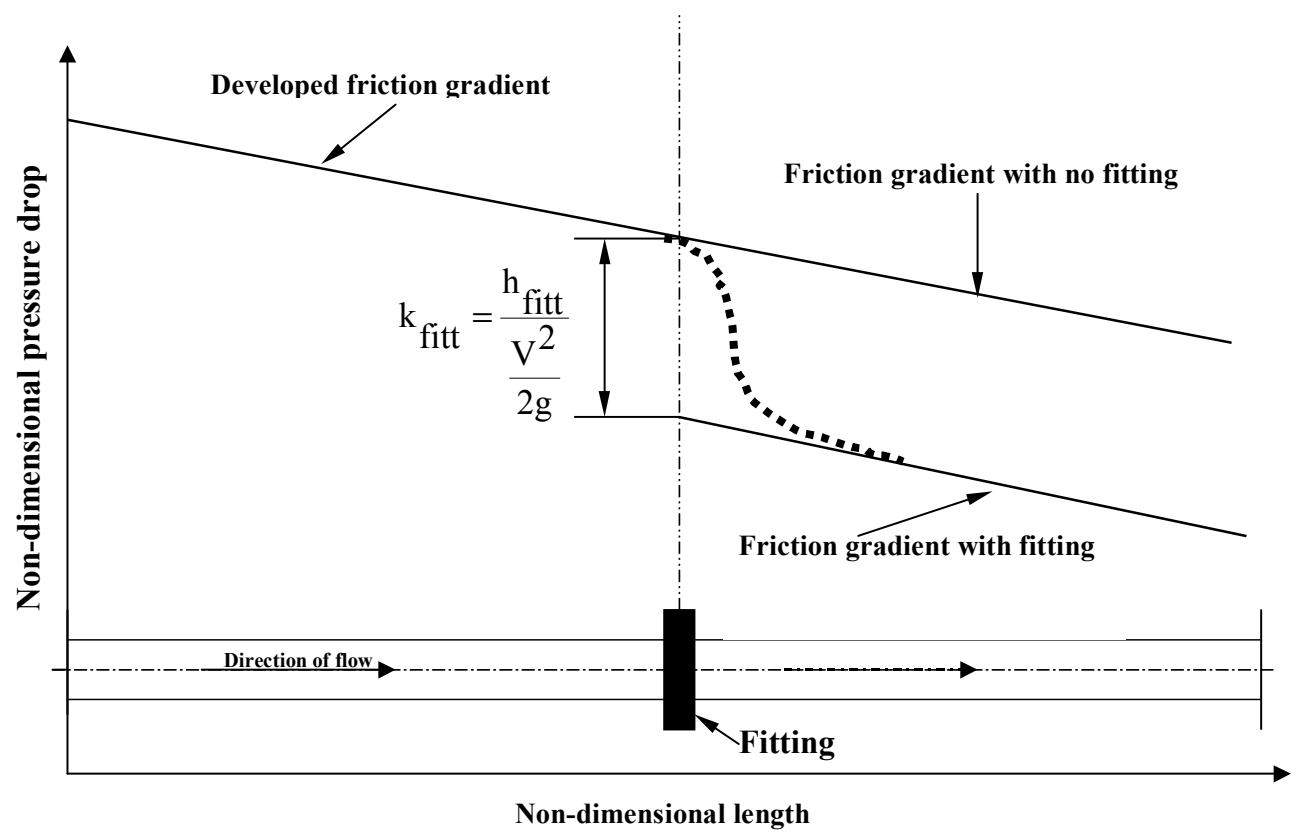

Figure 1 Definition of the loss coefficient (Miller, 1978)

\subsection{Laminar flow in fittings}

For laminar flow, Edwards et al. (1985) found the head loss, for both the Newtonian and non-Newtonian fluids tested, is given by:

$$
\frac{2 \mathrm{gh}_{\text {fitt }}}{\mathrm{V}^{2}}=\frac{\mathrm{C}_{\text {fitt }}}{\mathrm{Re}}
$$

and therefore:

$$
\mathrm{k}_{\text {fitt }}=\frac{\mathrm{C}_{\text {fitt }}}{\operatorname{Re}}
$$

Where $\mathrm{C}_{\text {fitt }}$ is the laminar flow loss coefficient constant and is a characteristic of a specific fitting including its dimensions. The Reynolds number appropriate to the flow behaviour of the fluid should be used.

\subsection{Dynamic similarity}

A Reynolds number appropriate for establishing dynamic similarity for the hydrodynamic analyses of viscoplastic fluid flow in valves has been developed (Fester and Slatter, 2009). This approach specifically treats the viscous stress as a unit, avoiding the separation of rheological parameters and placing emphasis on the effect of the yield stress:

$$
\mathrm{Re}_{3}=\frac{8 \rho \mathrm{V}_{\mathrm{ann}}^{2}}{\tau_{\mathrm{y}}+\mathrm{K}\left(\frac{8 \mathrm{~V}_{\mathrm{ann}}}{\mathrm{D}_{\text {shear }}}\right)}
$$

\subsection{Turbulent flow in fittings}

For turbulent flow through fittings, with the exception of bends, the loss coefficient is independent of the Reynolds number because inertial forces dominate. Experimental work showed that this is true for both Newtonian fluids (Miller, 1978) and non-Newtonian fluids (Fester et al., 2007; Mbiya et al., 2009). 


\subsection{Flow loss coefficients for diaphragm valves}

Loss coefficients for diaphragm valves have been measured (Fester et al., 2007; Mbiya et al., 2009). Figure 2 shows a graph of loss coefficient versus Reynolds number obtained for a $50 \mathrm{~mm}$ nominal bore Natco rubberlined, straight-through diaphragm valve, as measured (ibid).

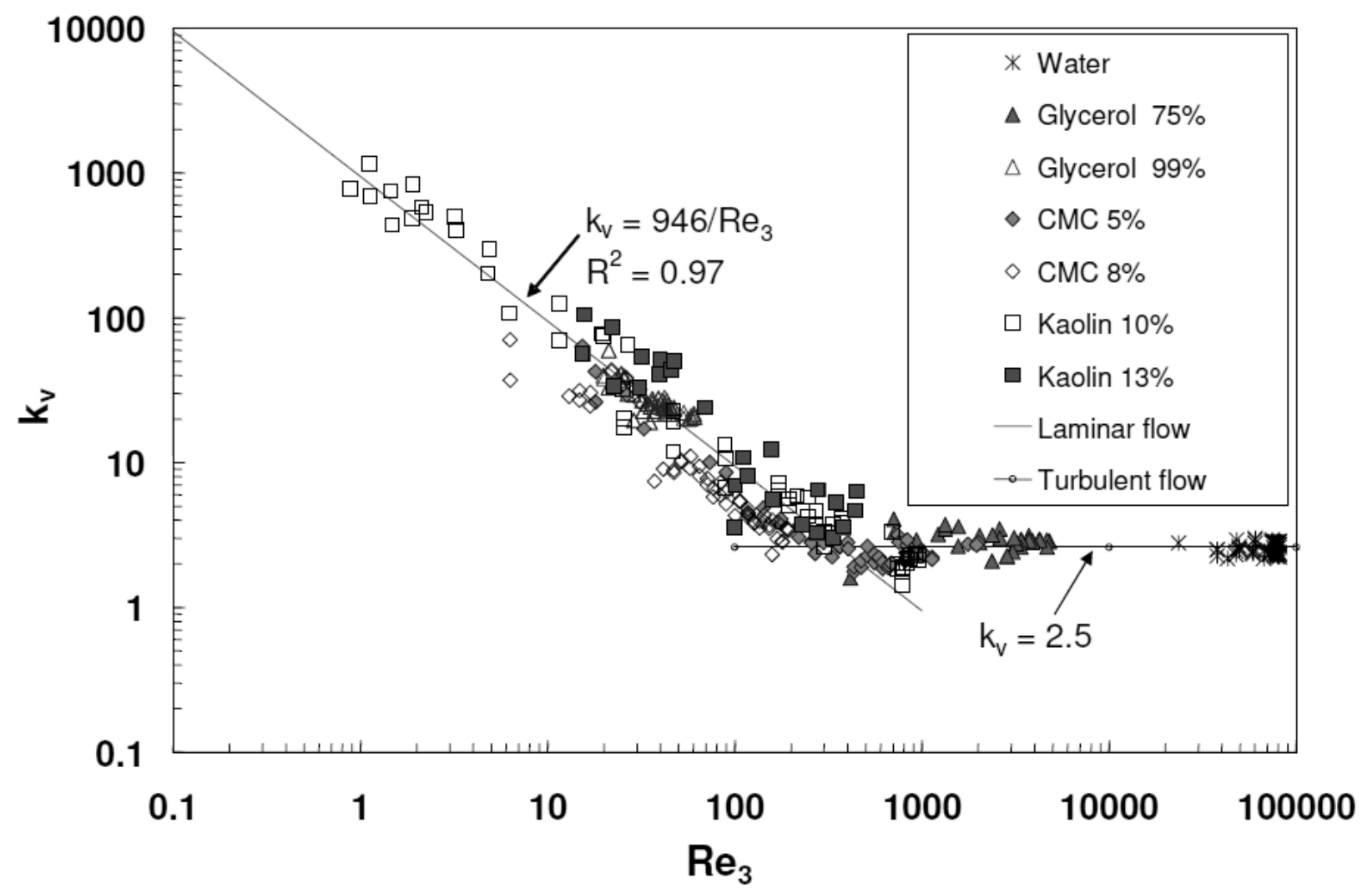

Figure 2 Loss coefficient versus Reynolds number plot obtained for a $50 \mathrm{~mm}$ nominal bore Natco rubber-lined, straight-through diaphragm valve (Fester et al., 2007; Mbiya et al., 2009)

Figure 2 shows that the loss coefficient for this valve in laminar flow is $k_{v}=946 / \operatorname{Re}_{3}$, and for turbulent flow is constant at $\mathrm{k}_{\mathrm{v}}=2.5$.

\section{Problem setting and analysis}

In order to illustrate the effect that the fittings loss has in laminar viscoplastic flow, a simple system consisting of $10 \mathrm{~m}$ of straight $50 \mathrm{~mm}$ pipe and five fittings with the properties of the above diaphragm valve is set and analysed. The fluid used for the analysis is a viscoplastic paste $\left(\tau_{\mathrm{y}}=100 \mathrm{~Pa}, \mathrm{~K}=1 \mathrm{~Pa} . \mathrm{s}, \mathrm{RD}=1.5\right)$. These values were chosen so as to present a relatively simple viscoplastic rheology which would yield laminar flow in a $50 \mathrm{~mm}$ pipe at $3 \mathrm{~m} / \mathrm{s}$.

The objective of the analysis was to obtain the Head Loss as a function of Flow Rate. The operating flow rate considered was $0.006 \mathrm{~m}^{3} / \mathrm{s}$ which corresponds to an operating average velocity $\mathrm{V}$ of $3 \mathrm{~m} / \mathrm{s}$ in a $50 \mathrm{~mm}$ pipe.

Since the value of the laminar flow loss coefficient is not available to most designers, the effect of incorrectly using the turbulent — constant — value for design in laminar flow will be highlighted. 


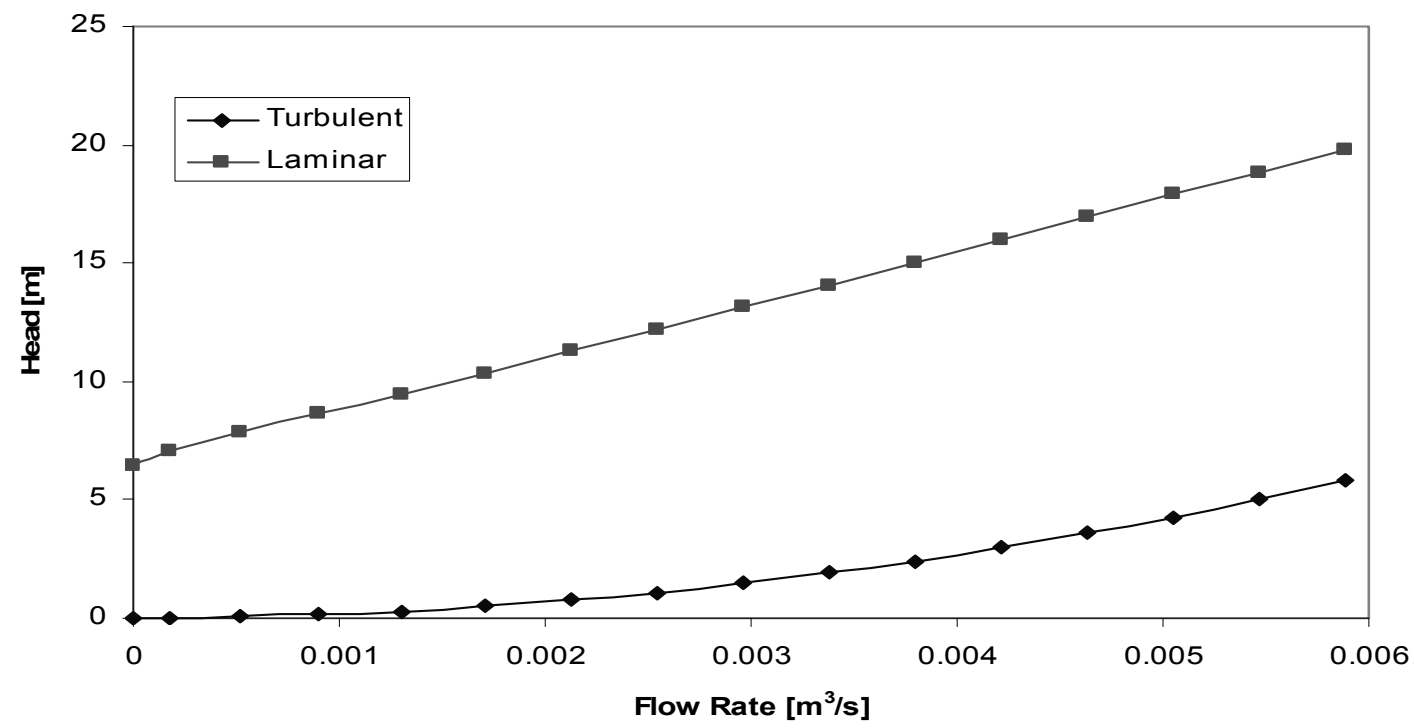

Figure 3 Fittings head losses in laminar and turbulent flow

Figure 3 shows the fittings head losses in both laminar and turbulent flow. This figure shows three principal differences between the fittings head losses in both laminar and turbulent flow:

1. The significant contribution of the laminar fittings loss to the start-up static head (at $Q=0$ ).

2. The very different shape presentation between laminar and turbulent flow.

3. The significant difference in magnitude which arises.

\subsection{Start-up static head}

In this example, the contribution of the laminar fittings loss to the start-up static head (at $\mathrm{Q}=0$ ) is $6.5 \mathrm{~m}$, as can be seen on the ordinate of Figure 3. Inspection of Equation (3) might lead one to expect a zero result at $\mathrm{Q}=0$, as portrayed by the turbulent locus in Figure 3 .

However, it must be understood that this non-zero value is a result of the combined effects of Equations (3), (7) and (8), and is a sign of the presence of a yield stress.

A fundamental study to characterise this important practical issue is under way.

\subsection{Shape presentation}

The inherently parabolic shape of the turbulent locus in Figure 3 is a direct consequence of the quadratic form of Equation (3) and the constant value of the loss coefficient $\mathrm{k}_{\text {fitt }}=2.5$ for this valve type in turbulent flow.

Equally, the inherently viscoplastic shape of the laminar locus in Figure 3 is a direct consequence of the hyperbolic form of Equation (7) combined with the emphasis of the role of the yield stress in Equation (8).

\subsection{Difference in magnitude}

Figure 3 shows that there are considerable differences in the magnitude of the fittings head losses in laminar and turbulent flow. A direst comparison of these magnitudes is shown in Figure 4. 


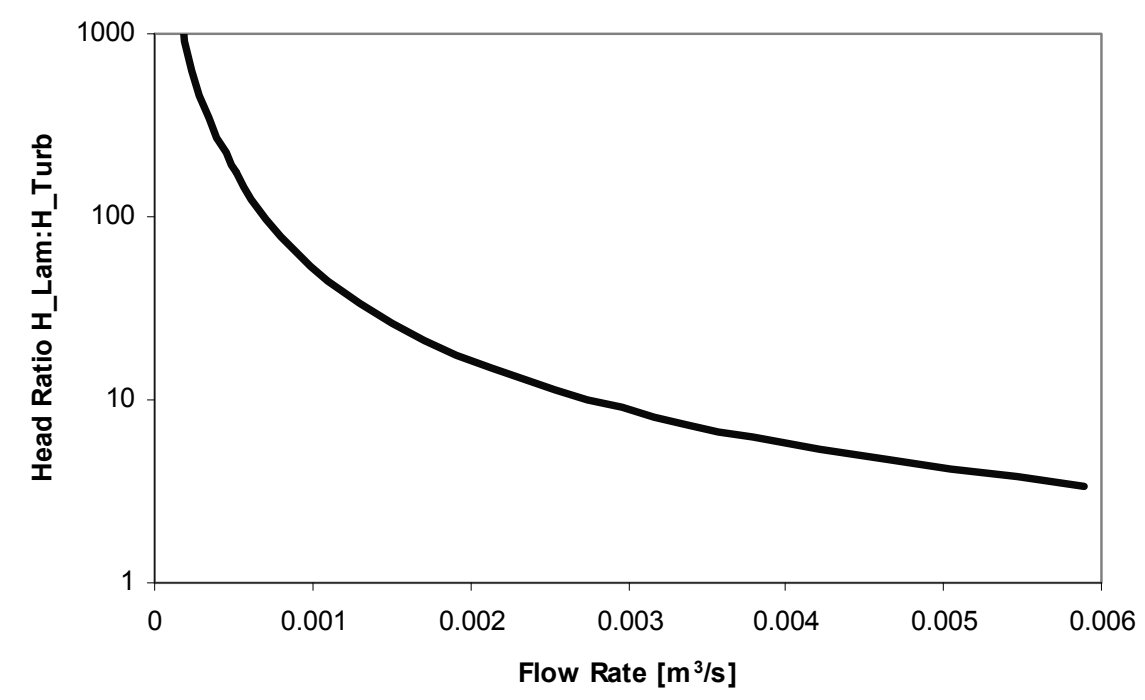

Figure 4 Comparison of the fittings head losses in laminar and turbulent flow shown in Figure 3

Figure 4 shows that the difference in magnitude is best expressed in orders of magnitude. In this example, the fittings head losses in laminar flow shown in Figure 3 and 4 exceed those in turbulent flow by several orders of magnitude.

\subsection{Pump power predictions}

Whilst these three issues discussed above are of importance, the issue of primary practical interest for paste piping design is the error in power prediction, if the design is performed using the extract from the Crane Co. (1999) paper. This situation is summarised for this example in Figure 5.

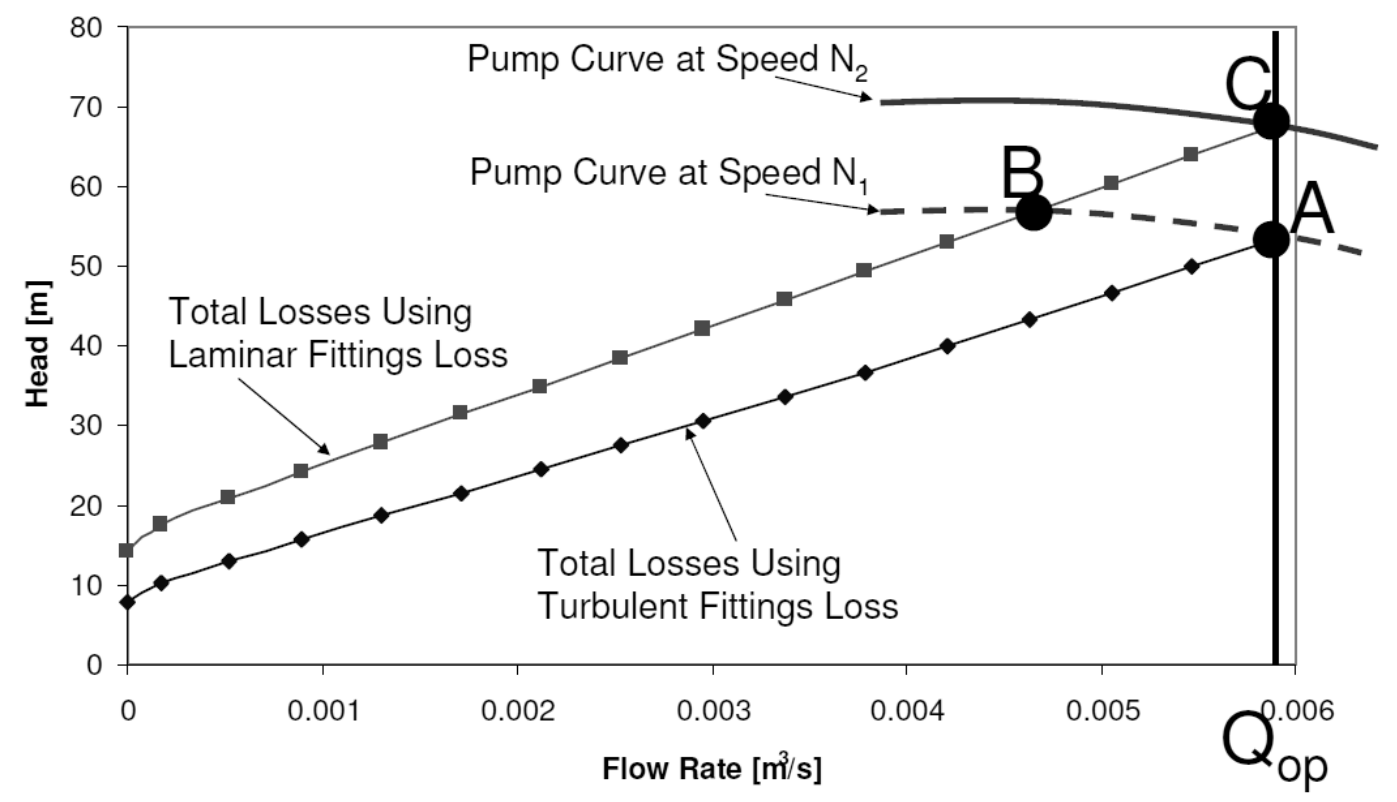

Figure 5 Pump operating points for both the laminar and turbulent design cases

Figure 5 shows the pump operating points for both the laminar and turbulent design cases, as derived from the practical design case example presented above.

The three possible operating points arising from the different design approaches to the practical design case example are highlighted in Figure 5 and designated Point A, Point B and Point C. The coordinates and 
resulting motor power (brake power) requirements from each of these three operating points are presented in Table 1.

Table 1 Pump operating point coordinates from Figure 6

\begin{tabular}{llll}
\hline Point & A & B & C \\
\hline Q $\left[\mathrm{m}^{3} / \mathrm{s}\right]$ & 0.0059 & 0.0046 & 0.0059 \\
$\mathrm{H}[\mathrm{m}]$ & 53 & 57 & 67 \\
Fluid power $[\mathrm{kW}]$ & 4.6 & 3.9 & 5.8 \\
Pump efficiency & $65 \%$ & $50 \%$ & $55 \%$ \\
Brake power $[\mathrm{kW}]$ & 7.1 & 7.7 & 10.6 \\
\hline
\end{tabular}

If the design is performed using the extract from the Crane Co. (1999) paper, the (incorrect) design operating point will be at Point A for this example, as shown in Figure 5 and Table 1.

If the designer follows the information published by the authors (Fester et al., 2007; Mbiya et al., 2009), the (correct) design operating point will be at Point $\mathrm{C}$ for this example, as shown in Figure 5 and Table 1.

This presents at least two problems of profound practical importance:

1. If the designer follows the first (incorrect) approach, then Figure 5 shows that - in reality - the pump will actually operate, not at Point A, but at Point B, at pump speed N1. Point B presents an operating flow rate penalty exceeding $20 \%$ whilst being almost $10 \%$ under-powered, as shown in Table 1.

2. In order to achieve the desired flow rate, the operating point will need to move from Point $\mathrm{B}$ to Point C, i.e. the speed would need to be significantly increased to pump speed N2. This increase in pump speed will require 50\% more brake power, as shown in Figure 5 and Table 1.

The important practical message here is that the pump motor would be $50 \%$ undersized.

All of these issues are further exacerbated by the shallow intersection angle which the laminar flow system curve presents to a centrifugal pump curve, as shown Figure 5. This will result in unstable operation, as small changes in head (i.e. small changes in material consistency) will result in significant changes in operating point flow rate.

As indicated by other investigations over several decades (e.g. Edwards et al., 1985; Fester et al., 2008), in laminar flow all fittings show this increase in $\mathrm{k}_{\mathrm{v}}$ with decreasing Reynolds number, significantly greater (orders of magnitude greater) than in turbulent flow. Our conclusions regarding the significance of the impact on pump sizing would therefore appear to be representative of other fittings in general, but focussed research to substantiate this is required.

\section{Conclusions}

The literature available to the paste piping designer contains a direct contradiction. This dilemma has been illustrated using a practical paste piping design example. It has been shown that errors in pump motor sizing of the order of $50 \%$ can realistically be expected. Very little information is available on this vitally important practical issue, and much further research is urgently required. The authors are presently extending this investigation to include:

- identification of critical fitting types used in industry

- determination of the loss coefficients of these fittings used in these applications

- design guidelines for non-Newtonian fluids including fitting losses. 


\section{References}

Crane Co. (1999) Flow of Fluids Through Valves, Fittings and Pipe, Technical paper No. 410, Crane Co., Chicago, IL, USA.

Edwards, M.F., Jadallah, M.S.M. and Smith, R. (1985) Head losses in pipe fittings at low Reynolds numbers, Chem. Eng. Res. Des, 63, January, pp. 43-50.

Fester, V.G., Kazadi, D.M., Mbiya, B.M. and Slatter, P.T. (2007) Loss coefficients for flow of Newtonian and nonNewtonian fluids through diaphragm valves, Trans IChemE, Part A, Chemical Engineering Research and Design, 85(A9), pp. 1314-1324.

Fester, V.G., Mbiya, B.M. and Slatter, P.T. (2008) Energy losses of non-Newtonian fluids in sudden pipe contractions, Chemical Engineering Journal, Vol. 145, No. 1, pp. 57-63.

Fester, V.G. and Slatter, P.T. (2009) Dynamic Similarity for Non-Newtonian Fluids in Globe Valves, Trans IChemE, Part A, Chemical Engineering Research and Design, Vol. 87, pp. 291-297.

Govier, G.W. and Aziz, K. (1972) The Flow of Complex Mixtures in Pipes, van Nostrand Reinhold Co.

Massey, B.S. (1970) Mechanics of fluids, Second edition, van Nostrand Reinhold Co.

Mbiya, B.M., Fester, V.G. and Slatter, P.T. (2009) Evaluating resistance coefficients of control diaphragm valves, Can. J. Chem. Eng., Vol. 87, pp. 704-714.

Miller, D.S. (1978) Internal flow systems, Cranfield: BHRA Fluid Engineering.

Streeter, V.L. and Wylie, B. (1985) Fluid Mechanics, 6th edition, McGraw-Hill Inc., USA. 